\title{
ADJECTIVAL AND VERBAL NOUNS IN JAPANESE AND MULTI-LEVEL NOMINALIZATION*
}

\author{
SEIKI AYANO \\ Faculty of Humanities and Social Sciences \\ Mie University \\ 1577 Kurimamachiya-cho, Tsu \\ Mie 514-8507 \\ Japan \\ ayano@human.mie-u.ac.jp
}

\begin{abstract}
This paper shows that there is a subclass of adjectives in Japanese called adjectival nouns, which consists of adjectives mostly of foreign origin, and this subset of the adjectives is required to undergo nominalization by the merger of a null nominalizing suffix. This process of nominalization takes place either prior to the PF interface or at PF, depending on the types of null nominalizing suffixes that merge with adjectival nouns. The proposed multilevel nominalization analysis has desirable consequences for adjectival nouns, and can also be extended to a subclass of verbs in Japanese, which likewise are typically of foreign origin.
\end{abstract}

Keywords: adjectival/verbal noun, Japanese, nominalizaiton, morphology-syntax interface, multi-level lexical insertion

* Research for this paper was supported in part by a Grant-in-Aid for Scientific Research (B) from the Japan Society for the Promotion of Science (\#17320062). Earlier versions of this paper were presented at the 2006 LSA Annual Meeting, the 12th International Morphology Meeting, the 2006 LAGB Annual Meeting and the 39th meeting of the Kobe Area Circle of Linguistics. I would like to thank the participants at the above meetings, Joseph Emonds, Sarah Tsiang and an anonymous reviewer for their valuable comments. Furthermore, the section of this paper on Japanese verbal nouns (VNs) is partly based on Ayano-Kamiya (2006). I want to thank Masaaki Kamiya for having shared his expertise in verbal nouns. Needless to say, all the remaining inadequacies and errors are mine. Abbreviations used in glosses are as follows: acc: accusative, cop: copulative verb, dat: dative, fp: final particle, gen: genitive, ger: gerund, nml: nominalizing suffix, nom: nominative, pres: present, q: question particle, top: topic marker. 


\section{Introduction}

Since Chomsky and Halle's (1968) seminal work on the Germanic-Latinate divide in the English lexicon, there have been various attempts to find a parallel distinction in the lexicons of other languages (e.g., Itô-Mester 1995a;b on the Japanese phonological lexicon). Drawing on such attempts, the principal goals of this paper are to show (i) that such a distinction in the Japanese lexicon is reflected, for instance, in the way in which the adjective class is divided into adjectives (As) and adjectival nouns (ANs), and (ii) that ANs are required to undergo nominalization at some point during the course of derivation. ${ }^{1}$

Based on Chomsky-Halle (1968), Emonds (1985; 1986; 2005) argues that the English vocabulary is divided into two subsets: (i) the primary vocabulary that consists mostly of native morphemes, and (ii) the secondary vocabulary that consists mostly of foreign morphemes. Importantly, for the native speaker, grammatical and phonological behavior rather than historical provenance determines to which subset a morpheme belongs (Emonds 1986). Along these lines, Kubo (1992) claims that the adjective class in Japanese consists of two subclasses. To the primary vocabulary belong As that are mostly of native origin. For example, the As in (1) belong to this subclass. On the other hand, As in the secondary vocabulary are mostly of foreign origin, and ANs in Japanese are such As. For example, ANs such as kiree 'pretty', kenmee 'wise', and ganzyoo 'sturdy' in (2) are of Sino-Japanese origin, while naisu 'nice', sohuto 'soft' and sumuuzu 'smooth' in (2) are borrowed from English. ${ }^{2}$

1 The term 'adjectival noun' follows Martin (1975). Note that in pedagogical Japanese grammars, ANs are called adjectival verbs. This is because both As and ANs need the copula verb when they modify Ns (Kubo 1992). See Baker (2003a) for an argument about why this is so in Japanese, based on his theory of lexical categories (Baker 2003b); namely, Japanese As lack agreement features unlike As in English, and thus need a verbal element to enter into an attributive relationship with Ns.

${ }^{2}$ However, there are ANs of native origin. The examples in (i) are such ANs (Nishiyama 1999):
(i) (a) sizuka 'quiet'
(d) sukoyaka 'heathy'
(b) hisoka 'secret'
(e) tasika 'certain'
(c) haruka 'far'
(f) sawayaka 'fresh'

Further, there are loanwords that are As: 
(1) As:

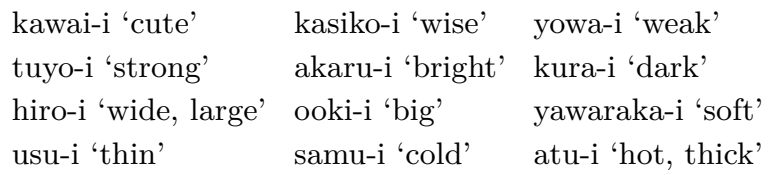

(2) ANs: kiree 'pretty' kenmee 'wise' ganzyoo 'sturdy'

zeizyaku 'feeble' koodai 'spacious' zyuunan 'flexible'

suki 'fond of' kirai 'dislike' heta 'poor at'

iya 'not fond of' seizyaku 'tranquil' taisetu 'important'

tokubetu 'special' sinkoku 'serious' naisu 'nice'

sikku 'chic' sohuto 'soft' sumuuzu 'smooth'

ereganto 'elegant' biggu 'big' surimu 'slim'

taito 'tight' mairudo 'mild'

It has been pointed out in the literature that ANs in Japanese exhibit category-ambiguous behavior between A and N (e.g., Kageyama 1993). I will show in this paper that such behavior of ANs in Japanese is rooted in nominalization that ANs must undergo at some point in the course of derivation, and that moreover this nominalization analysis can be extended to a subclass of verbs in Japanese.

This paper is structured as follows. Section 2 will present the morphosyntactic behavior of ANs in Japanese and will show that these ANs exhibit category-ambiguous behavior between $\mathrm{A}$ and $\mathrm{N}$. In section $\mathbf{3}$, a multi-level nominalization analysis of Japanese ANs is proposed, following Emonds (2000; 2005), in order to account for their morphosyntactic behavior. Section 4 will present desirable consequences of the proposed analysis for ANs. Section $\mathbf{5}$ will show that the proposed analysis can be extended to a subclass of verbs (Vs) in Japanese. Section $\mathbf{6}$ will conclude the present study.

\section{Adjectival nouns (ANs) in Japanese}

In this section, I will consider the morphosyntactic behavior of ANs in Japanese. First, I will show that on the surface, it appears that ANs pattern with Ns. Then, I will show that a closer examination of ANs

(ii) (a) ero-i 'erotic'

(b) syuuru-i 'surrealistic'

(c) nau-i 'up-to-date'

(d) guro-i 'grotesque'

Borrowed adjectives are typically classified as ANs, but this is not necessarily so. 
reveals that they exhibit morphosyntactic behavior that parallels that of As.

\subsection{N-like morphosyntactic behavior of ANs}

First, let us consider the inflectional paradigm of Japanese ANs. (3) summarizes the inflectional paradigms for ANs, Ns, As and Vs. Unlike As and Vs, which themselves are inflected for tense, Ns and ANs need the copula - $d a$ that bears tense. ${ }^{3}$ Presumably, the copula $-d a$ is marked by a zero morpheme for the present tense, and by -ta for the past tense.

\begin{tabular}{|c|c|c|}
\hline Present & $\begin{array}{l}\text { AN kiree 'pretty' } \\
\text { kiree-da }\end{array}$ & $\begin{array}{l}\text { N gakusee 'student } \\
\text { gakusee-da }\end{array}$ \\
\hline Past & kiree-dat-ta & gakusee-dat-ta \\
\hline Gerundive & kiree-de & gakusee-de \\
\hline Prenominal & kiree-na & gakusei-no \\
\hline & A kawai-i'cute' & V odor-u 'dance' \\
\hline Present & kawai-i & odor-u \\
\hline Past & kawai-kat-ta & odot-ta \\
\hline Gerundive & kawai-ku-te & odot-te \\
\hline Prenominal & kawai-i & odor-u \\
\hline
\end{tabular}

As a side note, it can be pointed out that the copula verb - $d a$ has been regarded as a synthetic form of -de ar-u (see Urushibara 1993 and

${ }^{3}$ As has been noted by Kubo $(1992,115)$ and others, PP can also be immediately followed by the copula $-d a$.

(i) Tugi-no kaigi-wa Tokyo-de-da.

next-gen meeting-top Tokyo-in-be-pres

'The next meeting is in Tokyo.'

Concerning this issue, Fukui (1986) and Fukui-Sakai (2003) point out that PP and some clausal projections in Japanese behave like nominal categories with respect to nominative case-marking. Note that this is also the case with the copula verb - da. As a side note, Emonds (1985, ch. 7) argues that C patterns with P. Furthermore, CP and DP have been shown to have parallel structures (Valois 1996, among others), which may account for the fact that CP as well as PP can be suffixed by the copula $-d a$ in Japanese, as shown in (ii):

(ii) Mondai-wa simekiri-madeni ronbun-o siager-areru-ka (dooka) dat-ta. question-top deadline-by paper-acc finish-be.able-q (whether) be-past 'The question was if (I) could finish the paper by the deadline.' 
Nishiyama 1999 for their analyses of -de ar-u). The first element -de of the non-contracted form - de ar- $u$ has been regarded as a postposition, a case-marker (Urushibara 1993) or a predicate head (Nishiyama 1999), while the second element - ar-u has been regarded as a copula verb. Note also that ANs and Ns take different prenominal suffixes, - $n a$ versus genitive $-n o$, respectively. The $-n a$ is considered to have been derived from the older copulative element nar- $u$, whose non-contracted form is $n i$ ar- $u$ 'in/at/dat cop-pres' (see Narahara 2002, ch. 8 for an exhaustive review of the literature).

Next, as Kageyama (1993) observes, notice that ANs can appear in the subject and object positions and can be case-marked. ${ }^{4}$ As shown in (4) and (5), ANs such as kenkoo 'healthy', genki 'vigorous', huketu 'unclean', and seizyaku 'tranquil' can appear in the subject and object positions with nominative and accusative case-markers, as illustrated by kenkoo-ga 'healthy-nom' in (4a), and kenkoo-o 'healthy-acc' in (5a).

(4) (a) Kenkoo/genki-ga itiban-da.

(cf. Kageyama 1993, 24)

healthy/vigorous-nom no.1-cop

'Being healthy/vigorous is a top priority.'

(b) Huketu-ga iya-da.

unclean-nom dislike-cop

'(I) dislike (something) being unclean.'

(5) (a) Kenkoo/genki-o izisi-ro!

(cf. idem.)

healthy/vigorous-acc maintain-imp

'Keep being healthy/being vigorous!'

${ }^{4}$ Note that not all ANs can appear in these positions and be case-marked, as can be seen in (i).

(i) a. *Hanako-wa sizuka-o kirat-ta.

Hanako-top quiet-acc dislike-past

'Hanako disliked being quiet."

(ii) b. *John-wa kenmee-ga homer-rare-ta

John-top wise-nom praise-pass-past

'John was praised for being wise.'

One may wonder if being associated with a nominative or accusative case-marker correlates with the prenominal suffix $-n o$, instead of $-n a$, for ANs. Uehara's (1998) extensive survey of 264 ANs shows that this is not the case; of the 151 ANs that can appear with the nominative or the accusative case-marker, 75 can be suffixed by -no in the prenominal position. 
(b) Seizyaku-o konom-u. tranquil-acc prefer-pres

'(Someone) prefers (something) being tranquil.'

\subsection{A-like morphosyntactic behavior of ANs: a closer look}

However, a closer look at the morphosyntactic behavior of ANs reveals that ANs and As form a natural class.

First, As and ANs can co-occur with degree phrases such as totemo 'very', kanari 'quite' and maamaa 'so-so', but Vs and Ns cannot, as illustrated in (6), (7), (8) and (9) (Kubo 1992):

(6) Hanako-ga totemo/kanari/maamaa kawai-i.

Hanako-nom very/quite/so.so cute-pres

'Hanako is very/quite/extremely cute.'

(7) Hanako-ga totemo/kanari/maamaa kiree-da.

Hanako-nom very/quite/so.so pretty-cop

'Hanako is very/quite/so.so pretty.'

(8) *Hanako-ga totemo/kanari/maamaa yom-u.

Hanako-nom very/quite/so.so read-pres

'Hanako reads very/quite/so.so.'

(9) *Hanako-ga totemo/kanari/maamaa gakusee-da.

Hanako-nom very/quite/so.so student-cop

'Hanako is a very/quite/so.so student.'

Note that there are cases where Vs and Ns allow degree phrases. Some Vs and Ns are in fact gradable, and thus can co-occur with such phrases. ${ }^{5}$

Second, only As and ANs can appear in comparative constructions (i.e., [DP/NP-yori A/AN] 'DP/NP-than A/AN' ), as illustrated in (10) and (11) (Kubo 1992). On the other hand, Vs and Ns do not typically appear in comparative constructions as shown in (12) and (13).

${ }^{5}$ In addition, there are certain non-gradable Vs that also allow degree phrases. This is not because the degree phrases modify the intensity of the action denoted by the verbs, but because they modify the quantity resulting from the action denoted by the verbs (see Urushibara 1993, 60). 
(10) (a) Hanako-wa Taroo-yori isogasi-i.

[A]

Hanako-top Taroo-than busy-pres

'Hanako is busier than Taro.'

(b) Kono-hon-wa ano-hon-yori muzukasi-i this-book-top that-book-than difficult-pres

'This book is more difficult than that book.'

(11) (a) Rondon-wa Pari-yori nigiyaka-da.

London-top Paris-than busy-cop

$[\mathrm{AN}]$

'London is busier than Paris.'

(b) Ken-wa Mari-yori sekkati-da.

Ken-top Mari-than impatient-cop

'Ken is more impatient than Mari.'

(12) (a) *Hanako-wa niku-o sakana-yori tabe-ru.

Hanako-top meat-acc fish-than eat-pres

'Hanako eats (more) meat than fish.'

(b) *Ziroo-wa Tokyo-e Nagoya-yori ik-u.

Ziroo-top Tokyo-to Nagoya-than go-pres

'Ziroo goes to Tokyo more than (to) Nagoya.'

(13) (a) *Hanako-wa Ziroo-yori seeto-da.

Hanako-top Ziroo-than student-cop

$\mathrm{AN}]$

'Hanako is (more of) a student than Ziroo'

(b) *Sakana-wa niku-yori tabemono-da.

fish-top meat-than food-cop

'Fish is more (typical) food than meat.'

Third, while As and ANs as in (14) and (15) can typically be suffixed by the verbal affix -gar-u 'feel', Vs and Ns as in (16) and (17) cannot. ${ }^{6}$

(14) (a) atu-i hot-pres

(b) kowa-i afraid-pres
$>$ atu-gar-u hot-feel-pres

$>$ kowa-gar-u afraid-feel-pres
$[\mathrm{A}]$

$[\mathrm{A}]$

${ }^{6}$ The verbal suffix - gar- $u$ 'feel' imposes a semantic restriction on co-occurring As and ANs, in that they must express the speaker's negative evaluation of the situation at issue (Urushibara 1993, 62). 
(15)
(a) meiwaku
$>$ meiwaku-gar-u
annoyed
annoyed-feel-pres
(b) human
$>$ human-gar-u
dissatisfied
dissatisfied-feel-pres

$[\mathrm{AN}]$

(16) (a) tukare-ru

$>*_{\text {tukare-gar-u }}$ become.tired-pres become.tired-feel-pres

(b) kanasim-u

$>$ *kanasim-gar-u

grieve-pres

grieve-feel-pres

(17) (a) hutan

$$
\begin{aligned}
& >\text { *hutan-gar-u } \\
& \text { burden-feel-pres }
\end{aligned}
$$
burden

(b) kunan

$>$ *kunan-gar-u hardship hardship-feel-pres

Fourth, only As and ANs can be nominalized by the nominalizing suffix -sa '-ness', as shown in (18) and (19), while Ns and Vs cannot, as in (20) and (21):

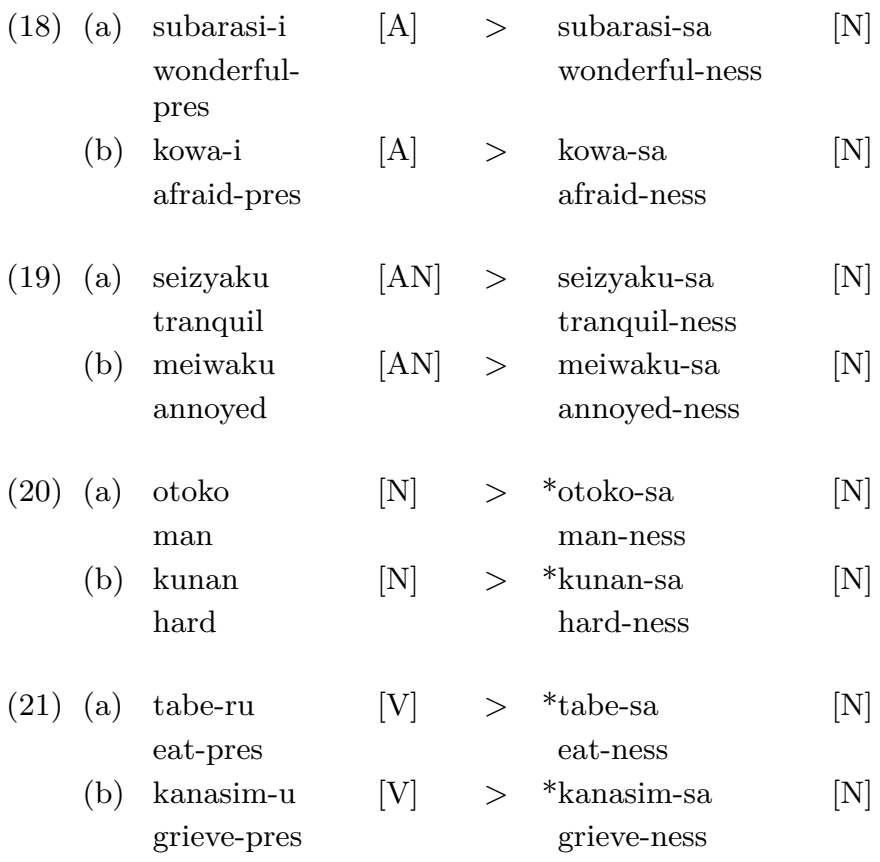

The present section has shown that while preliminary observations of ANs indicate they are N-like, a closer examination of their morphosyn- 
tactic behavior reveals that they constitute a subclass of As. Thus As and ANs as a subclass co-occur with specific degree phrases, occur in comparatives, and occur with specific affixes that are subcategorized for the adjective class only. I will propose in the following section that the particular morphosyntactic properties of ANs can best be captured assuming a category-shift from $\mathrm{A}$ to $\mathrm{N}$ at some point during the course of derivation.

\section{Multi-level nominalization of ANs in Japanese}

One way to capture the morphosyntactic properties of ANs is to posit feature-specification particular to ANs, which is exactly what Kageyama (1993) and Miyagawa (1987) have proposed. In the present section, I will first review their proposals before presenting my alternative proposal based on the multi-level lexical insertion theory.

\subsection{Previous proposals}

Chomsky's (1970) original proposal of feature specification for lexical items considers that the four lexical categories, namely, noun $(\mathrm{N})$, verb $(\mathrm{V})$, adjective $(\mathrm{A})$, and pre-/postposition $(\mathrm{P})$, can be defined by the combination of two features: $[ \pm \mathrm{N}]$ and $[ \pm \mathrm{V}]$, as shown in $(22)$.

$$
\begin{aligned}
& \text { (22) } \mathrm{N} \mathrm{V} \\
& \mathrm{N}+- \\
& \mathrm{A}++ \\
& \mathrm{V}-+ \\
& \mathrm{P}-
\end{aligned}
$$

Based on Chomsky (1970), Kageyama (1993) proposes that there is yet another independent feature $[ \pm \mathrm{A}]$, and that As and ANs share the same positive value for $[A]$, but carry different values for $[\mathrm{N}]$, namely, $[-\mathrm{N}]$ for As and $[+\mathrm{N}]$ for ANs. With this feature specification for ANs (i.e., $[+\mathrm{N},-\mathrm{V},+\mathrm{A}])$, Kageyama attempts to account for the category-ambiguous behavior of ANs. Kageyama's feature specification for N, A, AN, V and VN is shown in (23); note that VN stands for verbal noun, to which we will return in section $\mathbf{5}$. 


$$
\begin{aligned}
& \text { (23) } \mathrm{N} \quad \mathrm{V} \quad \mathrm{A} \\
& \mathrm{N}+-- \\
& \mathrm{A}--+ \\
& \mathrm{AN}+-+ \\
& \mathrm{V}-+ \\
& \mathrm{VN}++-
\end{aligned}
$$

In Miyagawa's (1987) proposal for the feature specification of lexical categories, illustrated in (24), As are unvalued for [N], while ANs are specified as $[+\mathrm{N},+\mathrm{V}]$.

(24) $\begin{array}{lll} & \mathrm{N} & \mathrm{V} \\ \mathrm{N}(\mathrm{VN}) & + & - \\ \mathrm{A} & & + \\ \mathrm{AN} & + & + \\ \mathrm{V} & - & + \\ \mathrm{P} & - & -\end{array}$

Details aside, in the proposals of both Miyagawa and Kageyama, ANs are defined as an independent category, specific to Japanese, in order to capture the fact that their morphosyntactic properties differ from those of canonical As and Ns. ${ }^{7}$ However, a stronger hypothesis would be to postulate that ANs are in fact As, are feature-specified as such, and undergo category-shift, as explained below.

\subsection{Multi-level nominalization}

The hybrid nature of ANs in Japanese can be explained if we assume that they undergo category-shift during the course of derivation. As background, let us first review Emonds' (2000; 2005) theory of multilevel nominalization, the basic idea of which is as follows.

In this theory, lexical items can be inserted at three different levels. First, lexical items are considered lexically inserted when they bear both semantic and syntactic features. These lexical items are basic lexical categories such as N, V, A and P. Second, lexical items are inserted in

${ }^{7}$ Note that Miyagawa's proposal of the lone feature $[+\mathrm{V}]$ for As is in line with van Riemsdijk's (1983) analysis of transitive As in German. See also Urushibara (1993) for an analysis that attempts to capture that ANs are different than As in terms of ordered feature specification. 
syntax if they lack semantic features, but have LF-interpretable syntactic features. Finally, lexical items with LF-uninterpretable syntactic features and no semantic features are inserted at PF. Consider (25) for a summary.

(25) Emonds' theory of multi-level insertion

Lexical insertion: Lexical items with semantic + syntactic features (Lexical categories $\mathrm{N}, \mathrm{V}, \mathrm{A}, \mathrm{P})$.

Syntactic insertion: Lexical items with syntactic features that are LF-interpretable (e.g., light verbs).

PF insertion: Lexical items with syntactic features that are not interpreted at LF.

On the basis of this theory of multi-level insertion, Emonds proposes, for example, that there are three types of nominalizing -ing in English.

(26) Three types of nominalizing -ing in English

(a) Lexical insertion of -ing

- result nominal, e.g., the/these/my $/{ }^{*}$ me standard/dark ink writings of $/{ }^{*}$ on Monday

(b) Syntactic insertion of -ing

- event nominal, e.g., the $/ *^{*}$ these $/ \mathrm{my} / *^{*}$ me quick $/ *^{*}$ quickly writing of a letter to John on/*of Monday

(c) $\mathrm{PF}$ insertion of -ing

- verbal gerund, eg., my $/ \mathrm{me} /{ }^{*}$ the $/ *^{*}$ these quickly $/{ }^{*}$ quick writing a letter to John on/* of Monday

The first type of -ing in (26a), which undergoes lexical insertion, is equipped with both a semantic feature and an LF-interpretable syntactic N-feature. This -ing suffix derives a result nominal. The second type of -ing in (26b) has an LF-interpretable syntactic N-feature without any semantic feature, and is inserted in syntax. This syntactic nominalization derives an event nominal. Finally, the third type of -ing in (26c) comes without a semantic feature and is equipped only with an LF-uninterpretable syntactic $\mathrm{N}$-feature, which derives a verbal gerund.

This paper will focus on the distinction between lexical and syntactic nominalization on the one hand, and PF nominalization on the other, since PF nominalization has a robust consequence, which is different from lexical and syntactic nominalization, in terms of the size of syntactic objects that undergo nominalization.

With regard to the issue of correlation between the size of nominalization and the level at which a given element undergoes nominal- 
ization, Yoon (1996) proposes that lexical nominalization takes place in the lexicon, while phrasal nominalization in syntax. While agreeing with his insights for the correlation, I will follow Emonds' claim that phrasal nominalization takes place at $\mathrm{PF}$, in that nominal properties of a given nominalized phrase do not contribute to syntax, which becomes more salient with respect to VNs (see especially the verbal anaphora facts in 5.3.2).

\subsection{My analysis of ANs}

My first proposal is that ANs, which are mostly As of foreign origin, constitute a subset of the adjective class, and that this subclass of As is required to undergo nominalization by the merger of a morphologically null $\mathrm{N}$ at different levels in the derivation. Following Emonds (2000), I also propose that a null nominalizing suffix with an LF interpretable Nfeature undergoes merger with ANs prior to PF, while a null nominalizing suffix with an LF uninterpretable N-feature undergoes merger with ANs at PF. Crucially, the former null nominalizing suffix targets an AN head, but the latter targets an entire AN phrase. The nominalization by the -ing suffix demonstrates the contrast at issue, as shown by (26a) and (26b) on the one hand, and (26c) on the other. Note especially that the gerund in (26c) retains the VP-like internal structure, taking the DP argument, as opposed to (26a) and (26b), which do not have the VP-like internal structure.

Returning to the morphosyntactic behavior of ANs in Japanese, I propose that the N-like properties of ANs are due to nominalization that they must undergo either prior to $\mathrm{PF}$ or at PF. The proposed analysis is illustrated in (27) and (28):

(27) AN nominalization prior to PF: Pre-PF

$$
\left[\begin{array}{cc}
\mathrm{A} & \mathrm{AN} \\
\downarrow
\end{array}\right.
$$

Pre-PF $\quad\left[{ }_{N}[A \quad A N][N \quad \emptyset]\right]$

(28) AN nominalization at PF:

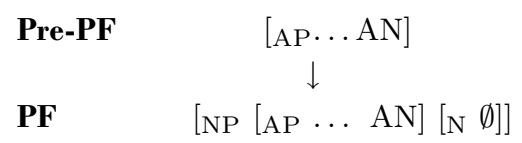


The derivations in (27) and (28) show that under the proposed analysis, all ANs are Ns at PF. ${ }^{8}$ Thus the N-like properties we have seen above, i.e., their co-occurrence with the copula verb and their case-marking, are $\mathrm{PF}$ phenomena, as shown below.

First, recall that ANs and Ns are suffixed by the same copula verb that bears tense. The copula, which can be regarded as LFuninterpretable, merges with Ns at PF. ${ }^{9}$ Since ANs are Ns at PF either by (27) or (28), they can be suffixed by the same copula verb, as illustrated in (29) and (30).

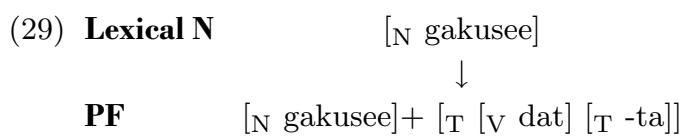

${ }^{8}$ As Caroline Heycock (p.c.) has pointed out to me, the question naturally arises as to why AN does not appear with the genitive case-marker -no in the pronominal position, but does appear with -na in the prenominal position (see Uehara (1998) for a list of 75 ANs that allow both -no and -na in the pronominal position, as already mentioned in fn. 4). The situation is problematic for the proposed nominalization analysis, in that all ANs should be Ns at PF. Furthermore, -na can be regarded as a morphological realization of Case (Yamakido 2005; to appear). I can only speculate here that $-n a$ is a reflection of the adjectival properties of AN that percolate up to the higher $\mathrm{N}$ node.

${ }^{9}$ I claim that the following facts support my analysis that the copula verb $-d a$ does not have semantic content; the presence or absence of the copula verb in sentences like those in (i) only marks the gender difference of the speaker (cf. Shibatani 1990).

(i) a. Taroo-wa gakusee-da-yo. [male speech]

Taroo-top student-cop-fp

'Taroo is a student.'

b. Taroo-wa gakusee- $\emptyset$-yo. [female speech]

Taroo-top student-cop-fp

'Taroo is a student.'

The anonymous reviewer points out that the above contrast seems like situationdetermined allomorphy, and that it provides no argument in itself either for or against attributing semantic content to $-d a$. Although the reviewer's point is well taken, I conjecture that it may be the case that - $d a$ is a dummy copula following Nishiyama (1999). He proposes that besides tense, there are two other heads associated with adjectives in Japanese: the lower predicate head (Bowers 1993), and the higher dummy copula whose function is simply to support tense. Applying his analysis to the predicate nominal gakusee 'student' in (i) and ANs, it may be that the predicate head is always phonologically null, and that the dummy copula exhibits situation-determined allomorphy (i.e., - $d a$ or null), as the reviewer suggests. 
(30) (a) Pre-PF-nominalized AN

PF

(b) PF-nominalized AN

PF

$$
\begin{aligned}
& \text { [N [A kiree } \left.]-\left[{ }_{\mathrm{N}} \emptyset\right]\right] \\
& \downarrow \\
& {[\mathrm{N}[\mathrm{A} \text { kiree }]-[\mathrm{N} \emptyset]]+\left[{ }_{\mathrm{T}}[\mathrm{V} \text { dat }][\mathrm{T}-\text { ta }]\right]} \\
& {[\mathrm{NP}[\mathrm{AP} \ldots \text { kiree }]-[\mathrm{N} \emptyset]]} \\
& \downarrow \\
& {[\mathrm{NP}[\mathrm{AP} \ldots \text { kiree }]-[\mathrm{N} \emptyset]]+\left[{ }_{\mathrm{T}}[\mathrm{V} \text { dat }]\left[\mathrm{T}_{\mathrm{T}} \text {-ta }\right]\right]}
\end{aligned}
$$

Second, as it has been observed in section 2, ANs can appear in the subject and object positions and be associated with the nominative and accusative case-markers, respectively. Provided that the case-markers in Japanese are inserted at PF (Fukui-Sakai 2003; Nakamura 2005), ANs, which are Ns at PF, can then be case-marked. Consider (31):

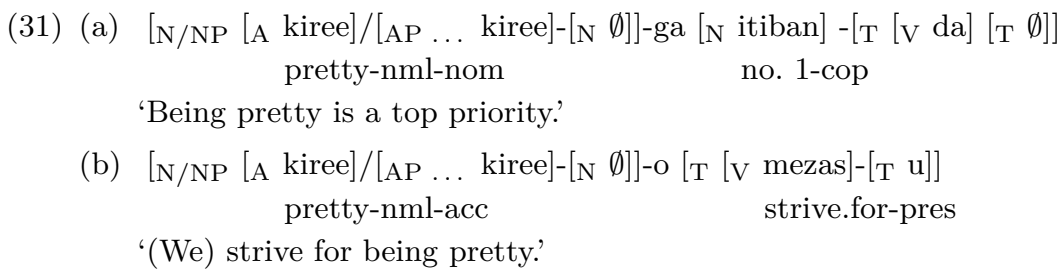

With regard to the four kinds of A-like behavior of ANs, provided that the above analysis of ANs is on the right track, they can be considered to reflect the properties of ANs in syntax and at LF. I will not provide a detailed analysis here, but will return to $-s a$ nominalization in the following section, as it is directly relevant to the proposed multi-level nominalization analysis of ANs.

\section{Consequences of the proposed analysis}

It follows from the PF-nominalization analysis of verbal gerunds in English that when ANs undergo nominalization at PF, they should display AP-like behavior internally, and NP-like behavior externally. Recall that ANs being As, they can take degree phrases and can also appear with the comparative expression DP/NP-yori 'DP/NP-than'. Assuming that both degree phrases and comparative expressions are AP-internal elements, we predict that ANs with a degree phrase and entire comparative constructions should be able to appear in the subject or object position and be case-marked; the null $\mathrm{N}$ merger at the PF interface is predicted to target a larger unit such as AP, and case-marking is considered to take 
place at PF following nominalization. The examples in (32a) and (32b) show that the prediction is correct. In (32a), the AN kiree 'clean' with the degree phrase totemo 'very' appears in the subject position and the whole adjectival phrase is suffixed by the nominative case-marker. Likewise, in (32b), the adjectival phrase involving a comparative of the form dare 'who', and the AN suteki 'charming' appears in the object position and is suffixed by the accusative case-marker.

(32) (a) [NP [AP totemo kiree]-[N $\emptyset]]$-ga suki very clean-nml-nom like

'(I) like (something) being extremely clean.'

(b) $[\mathrm{NP}[\mathrm{AP}$ dare-yori-mo suteki]-[N $\emptyset]]-\mathrm{o}$ mezasi-te anyone-than-foc charming-nml-acc aim-ger 'aiming to be more charming than anybody'

It should be noted that under the proposed analysis, the ANs kiree 'clean/pretty' and suteki 'charming' in (33) with the modifier anata-no 'you-gen' can be captured as having undergone nominalization prior to $\mathrm{PF}$ :

(33) [NP anata-no [N [A kiree/suteki]-[N $\emptyset]]$-no himitu you-gen pretty/charming-nml-gen secret 'the secret of your prettiness/charmingness'

A logical question to ask at this point is where the nominalizing suffix -sa stands in relation to the proposed null $\mathrm{N}$ introduced either prior to or at PF. As shown in section $\mathbf{2}$, the -sa suffix in Japanese nominalizes As and ANs only. Consider (34), in which the A kawaii 'cute' and the AN kiree 'pretty/clean' are nominalized:

(34) (a) kawai-sa

(b) kiree-sa pretty/clean-nml

Let us contrast the proposed null $\mathrm{N}$ with the nominalizing suffix -sa. The question here is at what level the -sa suffix is merged with ANs. The fact that the sentences in (32) become ungrammatical when -sa replaces the PF-inserted null $\mathrm{N}$, as illustrated in (35), suggests that $-s a$ is introduced prior to $\mathrm{PF}$. 
(35) (a) *[N [AP totemo kiree $]-[\mathrm{N}$ sa $]]$-ga suki very clean-nml-nom like

'(I) like extreme cleanliness.'

(b) $*{ }_{\mathrm{N}}[$ AP dare-yori-mo suteki $]-[\mathrm{N}$ sa $\left.]\right]_{-}$mezas-ite anyone-than-foc charming-nml-acc aim-ger

'aiming to be more charming than anybody'

From the results in (35), it is expected that (33) remains grammatical when the pre-PF-inserted null $\mathrm{N}$ is replaced by the overt nominalizing suffix $-s a$, as illustrated in $(36):^{10}$

(36) $[\mathrm{NP}$ anata-no [N [A kiree/suteki]-[N sa]]]-no himitu you-gen pretty/charming-nml-gen secret

'the secret of your prettiness/charmingness'

10 The anonymous reviewer asks if there is a semantic difference between (33) and (36). Although the exact nature of the difference is not immediately obvious, the following contrast in (i) is suggestive of the difference in question:

(i) (a) ni-kasyo-no kiree-sa-ga medat-u.

two-cl-gen clean-nml-nom stand.out-pres

'Cleanliness of two places stands out (among others).'

(b) *ni-kasyo-no kiree- $\emptyset$-ga medat-u.

two-cl-gen clean-nml-nom stand.out-pres

'Cleanliness of the two places stands out (among others).'

The morphosyntactic behavior of the nominalized AN kiree-sa 'clean-nml' in (ia) parallels that of the result nominal in (26a), in that both of them can be pluralized. Under Emonds' analysis, the -ing suffix, which derives result nominals, is equipped with a semantic feature as well as a syntactic N-feature interpretable at LF, and is inserted in the lexicon. As for the -sa suffix, Kageyama's (1982, 21821) analysis is in support of the insertion of $-s a$ in the lexicon. On the other hand, (ib) resists pluralization just like the event nominal in (26b) and the verbal gerund in (26c). In fact, as the reviewer suggests, (33) can be taken as a case of PF nominalization, having the ' $\mathrm{X}$ being Adj' structure. That is, the entire AN phrase has undergone nominalization at PF. If this is the case, then the genitive case on anata-no 'you-gen' in (33) may be assigned in [Spec, D], just as the genitive case assigned to the subject in constructions in which the $g a / n o$ "nominative/genitive" conversion is observed (Miyagawa 1993; Ochi 2001). One obvious problem of applying the $g a /$ no-conversion analysis to (33) is that anata 'you' in it cannot be associated with nominative case. In view of the above facts, my proposed analysis for (33) seems to be on the right track. 
Further, provided that the -sa suffixation nominalizes ANs prior to PF, it is predicted that other modifiers of $\mathrm{N}$ such as kono 'this' and anata-no 'you-gen' should be able to co-occur with ANs. Consider (37): ${ }^{11}$

(37) (a) kono suteki-sa-ga suki-da.

this attractive-nml-nom like-cop

'(I) like this attractiveness.'

(b) anata-no kiree-sa-o urayamasi-gat-ta.

you-gen pretty-nml-acc jealous-feel-past

'(Someone) felt jealous of your prettiness.'

To summarize, I have shown in this section that the proposed nominalization analysis has some desirable consequences. In addition, the multi-level nominalization analysis for ANs indicates that the nominalizing suffix -sa merges with ANs prior to PF. We will see in the following section (i) that the primary-secondary divide can also be observed in the verb class in Japanese, and (ii) that the proposed analysis can also account for a subclass of Vs that are typically of foreign origin.

\section{Verbal nouns (VNs) in Japanese}

Section $\mathbf{5}$ will show that the multi-level nominalization analysis can be extended to account for the morphosyntactic behavior of a subclass of Vs in Japanese called verbal nouns (VNs). First of all, there are two types of verbs in Japanese, as illustrated in (38). Note that the verbs in (38b) can be decomposed into VN and the light verb suru 'do'. Furthermore,

${ }^{11}$ With an LF-interpretable null $\mathrm{N}$, the ANs should be nominalized before PF and the modifiers kono 'this' and anata-no 'you-gen' should be able to co-occur. Indeed, there are ample examples, in which the two ANs illustrated in (35) are modified by kono and anata-no. However, the sentences in (i) are ungrammatical, which is not expected. I leave this question for future research.

(i) (a) *kono suteki-ga suki-da.

this attractive-nom like-cop

'(I) like this being attractive.'

(b) *anata-no kiree-o urayamasi-gat-ta. you-gen pretty-acc jealous-feel-past

'(Someone) felt jealous of your being pretty.' 
just like the AN subset in Japanese, the VN subset consists mostly of loanwords. ${ }^{12}$

(38) Two types of verbs in Japanese

(a) $-(\boldsymbol{r}) \boldsymbol{u}$ verbs

aruk-u 'walk'

kir-u 'cut'

ki-ru 'wear'

tob-u 'jump, fly'

(b) -suru verbs: $\mathrm{VNs}+$ the light verb - suru $^{13}$

doraibu-suru 'go for a drive' [English]

dansu-suru 'dance' [English]

renraku-suru 'contact' [Sino-Japanese]

tentoo-suru 'fall' [Sino-Japanese]

In what follows, I will first review morphosyntactic properties of VNs, which exhibit hybrid morphosyntactic behavior between $\mathrm{V}$ and $\mathrm{N}$.

${ }^{12}$ As in the case of ANs, there are exceptions. Although the following verbs in (i) are of foreign origin, they are classified as $-(r) u$ verbs:
(i) (a) memo-ru 'take notes'
[English]
(b) misu-ru 'make a mistake'
[English]
(c) makku-ru 'eat at McDonald's' [English]
(d) sabo-ru 'sabotage'
[French]

13 Note that the VN-suru 'VN-do' construction allows unaccusative VNs as well as transitive VNs (including unergative VNs (Chomsky 1995, among others)), whereas the VN-o suru 'VN-acc do' construction rules out unaccusative VNs. There have been various attempts to capture the contrast in the generative literature (Kageyama 1982; 1993; Miyagawa 1987; Grimshaw-Mester 1988). Given my proposal that VNs are Vs, one plausible analysis is that there are two kinds of suru: one kind that can select $\mathrm{VP}$ and $v \mathrm{P}$, which derives the $\mathrm{VN}$-suru construction and, thus, rules in unaccusative VNs, and the other that selects only $v \mathrm{P}$, thus ruling out unaccusative $\mathrm{VNs}$ that are without $v$. The former -suru is a light verb and thus naturally imposes fewer selectional restrictions than the latter regular verb suru. If $\mathrm{VNs}$ as well as ANs are required to undergo nominalization, the question naturally arises as to why VNs do not undergo nominalization in the VN-suru construction. I propose that -suru in the VN-suru construction is inserted at PF (see Takahashi 2000), under the condition that suru in the VN-o suru construction is not selected and merged in syntax. The suru-insertion at PF blocks PF nominalization.

Acta Linguistica Hungarica 54, 2007 


\subsection{N-like morphosyntactic behavior of VNs}

First of all, VNs are N-like, in that they can be suffixed by the copula verb - $d a$. In other words, VNs cannot inflect on their own and need the copula verb to bear tense just like Ns do:

$\begin{array}{lll} & \text { VN benkyoo 'study' } & \text { N gakusee 'student' } \\ \text { Present } & \text { benkyoo-da } & \text { gakusee-da } \\ \text { Past } & \text { benkyoo-dat-ta } & \text { gakusee-dat-ta } \\ \text { Gerundive } & \text { benkyoo-de } & \text { gakusee-de } \\ \text { Prenominal } & \text { benkyoo-no } & \text { gakusei-no }\end{array}$

Second, VNs can be case-marked as illustrated in (40). In (40a), the VN benkyoo 'study' appears in nominative case, and in (40b), the same VN appears in accusative case.

(40) (a) Taroo-wa benkyoo-ga yoku deki-ru.

Taroo-top study-nom well be.good.at-pres

'Taroo is very good at studying.'

(b) Benkyoo-o ganbar-e!

study-acc work.hard-imp

'Study hard!'

Next, I will show that VNs exhibit V-like morphosyntactic behavior, too.

\subsection{V-like morphosyntactic behavior of VNs}

Interestingly, in (41a), the VN phrase in the aspectual affix clause, which involves the aspectual N, -tyuu 'middle', exhibits NP-like internal and external behavior, but also displays VP-like properties.

(41) (a) ?Taroo-no eego-no benkyoo-tyuu, Hanako-mo soo s-ita.

Taroo-gen English-gen study-middle Hanako-also so do-past

'During Taroo's study of English, Hanako did so.'

(b) Taroo-ga keeki-o tabeta. Hanako-mo soo s-ita.

Taroo-nom cake-acc ate Hanako-also so do-past

'Taroo ate a cake. Hanako did so.'

(c) Taroo-wa gakusee-da. *Hanako-mo soo s-ita.

Taroo-top student-cop Hanako-also so do-past

'Taroo is a student. So did Hanako.' 
(41a) shows that the verbal anaphoric expression soo sita 'did so' can refer to the VN phrase in the aspectual affix clause. Crucially, the verbal anaphoric expression soo suru 'do so' can only refer to the preceding VP as in (41b), not to the preceding NP as in (41c) (Shibatani 1976).

Second, in aspectual affix clauses, VNs can take a nominative subject and an accusative object. ${ }^{14}$ Example (42a) shows that with the aspectual N -sai 'occasion', the VN hihan 'criticism' can take the nominative subject gakusee-ga 'student-nom' and the accusative object sensei-no ronbun-o 'teacher-gen paper-acc'. Likewise in (42b), with the aspectual $\mathrm{N}$-tyuu 'middle', the VN unten 'drive' can take the nominative subject Taroo-ga 'Taroo-nom' and the accusative object kuruma-o 'car-acc' (cf. Hasegawa 1999).

(42) (a) gakusee-ga sensee-no ronbun-o hihan-no-sai-ni student-nom teacher-gen paper-acc criticism-gen-occasion-on 'on the occasion of the student's criticism of the teacher's paper'

(b) Taroo-ga kuruma-o unten-tyuu-ni Taroo-nom car-acc drive-middle-in 'in the middle of Taroo's driving a car'

Having observed the hybrid morphosyntactic behavior of VNs, next we will see how the proposed multi-level nominalization analysis has some desirable consequences.

\subsection{Consequences of the multi-level nominalization analysis for VNs}

\subsubsection{Double accusative constructions with VNs}

Notice that the multi-level nominalization analysis proposed in this paper predicts that VNs should also display a contrast in their behavior depending on at which level they undergo nominalization. This prediction is borne out.

The sentences in (43) are considered to involve the nominalization of VNs at PF by a null nominalizing suffix with an LF-uninterpretable syntactic N-feature. Their behavior is parallel to the verbal gerund facts in English observed earlier in the paper: they are NP-like externally and VP-like internally. More specifically, the VNs syookai 'introduction'

${ }^{14}$ Note that with the aspectual Ns, -aida 'between', -mae 'before', - $z i$ 'when', and toki 'when', VNs cannot take either a nominative subject or an accusative object (Hasegawa 1999). 
and benkyoo 'study' take the accusative objects, John-o 'John-acc' and suugaku-o 'math-acc', respectively, and co-occur with the adverbial modifiers rather than the adjectival ones.

\section{(43) PF-nominalization}

(a) ?/?? Taroo-wa Hanako-ni John-o subaya-ku/*subaya-i syookai-o s-ita. Taroo-top Hanako-dat John-acc quickly/quick introduction-acc do-past 'Taroo introduced Hanako to John quickly.'

(b) ?/??Hanako-wa gakko-de suugaku-o tanosi-ku/*tanosi-i benkyoo-o s-ite-i-ru. Hanako-top school-at math-acc happily/happy study-acc do-ger-be-pres 'Hanako is enjoying studying math at school.'

On the other hand, the pre-PF nominalization facts in (44) show NP-like behavior both within and outside of the VN phrase: the DP and PP objects of the VNs appear in genitive case, and the VNs are modified by the adjectives, not by the adverbs.

\section{(44) Pre-PF-nominalization}

(a) Taroo-ga Hanako-e-no John-no subaya-i/*subaya-ku syookai-o s-ita. Taroo-nom Hanako-to-gen John-gen quick/quickly introduction-acc do-past 'Taroo did a quick introduction of John to Hanako'

(b) Hanako-ga gakko-de-no suugaku-no tanosi-i/*tanosi-ku benkyoo-o s-ite-i-ru. Hanako-nom school-at-gen math-gen happy/happily study-acc do-ger-be-pres 'Hanako is doing the happy studying of math at school.'

The structures for (43) and (44) can be schematically represented in (45) and (46), respectively. ${ }^{15}$

\section{(45) PF-nominalization}

$\left.\ldots\left[\mathrm{NP}[v \mathrm{P} \ldots[\mathrm{VP} \ldots[\mathrm{V} \mathrm{VN}]]][]_{\mathrm{N}} \emptyset\right]\right]$-acc suru

15 The anonymous reviewer questions how the verb suru 'do' in (44) can impose selectional restrictions mentioned in $\mathrm{fn} .13$ since it appears to select the nominalized VN head as shown in (46). It should be noted that (46) is a PF representation. The derivation of (46) proceeds as follows:

(i) (a) $\left[{ }_{v \mathrm{P}} \ldots[\mathrm{VP} \ldots[\mathrm{V}\right.$ VN] $\left.]]\right]($ Syntax \#1) $\rightarrow$

(b) $\left[\mathrm{VP}\left[{ }_{v \mathrm{P}} \ldots[\mathrm{VP} \ldots[\mathrm{v}\right.\right.$ VN $\left.]]\right]$ suru $]($ Syntax \#2) $\rightarrow$

(c) $\left[\mathrm{VP}\left[\mathrm{NP} \ldots\left[\mathrm{NP} \ldots\left[\mathrm{N}_{\mathrm{N}}[\mathrm{V}\right.\right.\right.\right.$ VN]-[N $\left.\left.\left.\emptyset]\right]\right]\right]$ suru $](\operatorname{Syntax} \# \mathbf{3}) \rightarrow$

(d) $[\mathrm{vP}[\mathrm{NP} \ldots[\mathrm{NP} \ldots[\mathrm{N}[\mathrm{V}$ VN]-[N

As shown in (ib), suru 'do' merges with $v \mathrm{P}$, which is followed by syntactic nominalization whose categorial feature percolates up to the extended projection of $\mathrm{VN}$, namely $v \mathrm{P}$, as illustrated in (ic). 
(46) Pre-PF-nominalization

$\cdots[\mathrm{NP} \cdots[\mathrm{N}[\mathrm{V}$ VN] $[\mathrm{N} \emptyset]]-$ acc suru

I should note that the degraded judgments for the examples in (43) are rooted in the double-accusative constraint in Japanese (Harada 1973). Without the intervening adverbs between the two DPs in accusative case, the two sentences are further degraded. However, the double accusative sentences in (43) improve immensely when they are clefted as in (47). Note also that the double accusative construction in a causative sentence such as (48a) is much worse than the double accusative sentences in (43), and can never improve, even if they are clefted as in (48b). This suggests that the sentences in (43) are made marginal for some surface reason; the syntactic derivations themselves are fine (see Saito-Hoshi 2000).

(47) (a) Taroo-ga Hanako-ni subaya-ku syookai-o s-ita-no-wa John-o-da. Taroo-top Hanako-dat quickly introduction-acc do-past-nml-top John-acc-cop 'It was John whom Taroo quickly introduced to Hanako.'

(b) Hanako-ga gakko-de tanosi-ku benkyoo-o s-ite-iru-no-wa suugaku-o-da. Hanako-nom school-at happily study-acc do-ger-be-nml-top math-acc-cop 'It is math that Hanako is happily studying at school.'

(48) (a) Hanako-ga Taroo-ni/*-o hon-o yom-ase-ta. Hanako-nom Taroo-dat/-acc book-acc read-make-past 'Hanako made Taroo read a book.'

(b) *Hanako-ga Taroo-o yom-ase-ta-no-wa hon-o-da. Hanako-nom Taroo-acc read-make-past-nml-top book-acc-cop 'It is a book that Hanako made Taroo read.'

\subsubsection{The verbal anaphoric expression soo suru 'do so'}

Concerning the verbal anaphoric expression soo suru 'do so', it should follow from the analysis that the somewhat degraded grammaticality of (41a), in which the VN benkyoo 'study' is considered to have undergone pre-PF nominalization and, thus, is embedded within NP, should improve if the VN undergoes nominalization at PF. This prediction is borne out, as shown by the contrast between (41a) repeated here as $(49 \mathrm{a})$ and $(49 \mathrm{~b}) .{ }^{16}$ Note that $\left(49^{\prime}\right)$ illustrates their representations in syntax and at LF.

${ }^{16}$ The slightly degraded grammaticality of (49a) was pointed out by Masaki Sano (p.c.). 
(49) (a) ?'Taroo-no eego-no benkyoo-tyuu, Hanako-mo soo s-ita. Taroo-gen English-gen study-during Hanako-also so do-past 'During Taroo's studying of English, Hanako did so'

(b) Taroo-ga eego-o benkyoo-tyuu, Hanako-mo soo s-ita. Taroo-nom English-acc study-during Hanako-also so do-past 'During Taroo's studying English, Hanako did so.'

$\left(49^{\prime}\right)(\mathrm{a}){ }^{?}[\mathrm{NP}$ Taroo-no eego-no [N [V benkyoo]-[N $\left.\emptyset]\right]$-tyuu, Hanako-mo soo s-ita. Taroo-gen English-gen study-nml-middle Hanako-also so do-past 'During Taroo's studying of English, Hanako did so.'

(b) [vP Taroo-ga eego-o benkyoo]-tyuu, Hanako-mo soo s-ita. ${ }^{17}$ Taroo-nom English-acc study-nml-middle Hanako-also so do-past 'During Taroo's studying English, Hanako did so.'

Interestingly, we can observe a similar contrast in English. Consider the contrast between (50a) and (50b), and their representations in syntax and at LF shown in $\left(50^{\prime} \mathrm{a}\right)$ and $\left(50^{\prime} \mathrm{b}\right)$, respectively. ${ }^{18}$

(50) (a) ?John's writing of a novel was quick, but Mary's doing so was even quicker.

(b) John's writing a novel was quick, but Mary's doing so was even quicker.

$\left(50^{\prime}\right)(\mathrm{a})$ ? [NP John's [N [V writ]-[N ing $]$ of a novel] was quick, but Mary's doing so was even quicker.

(b) [vP John's writing a novel] was quick, but Mary's doing so was even quicker.

The sentence in (50a) involves pre-PF nominalization; the nominalizing suffix -ing has targeted the verb write only, a structure parallel to that of (49a). On the other hand, in (50b), the nominalizing suffix -ing has targeted the VP in much the same way that the null nominalizing suffix nominalizes the VP in (49b). The V is embedded within NP as illustrated in $\left(50^{\prime} \mathrm{a}\right)$, while it remains $\mathrm{V}$ throughout in syntax and at $\mathrm{LF}$ as in $\left(50^{\prime} \mathrm{b}\right)$, hence the contrast in grammaticality.

17 Note that the aspectual affix -tyuu in this clause is T, not N. This T licenses the nominative case for Taroo-ga 'Taroo-nom' that actually moves out of the NP to Spec of TP, which is not shown in the structure given here.

18 The contrast in (50) was observed by Brian Agbayani (p.c.) who has also pointed out that the following example of $\mathrm{Fu}$ et al. (2001), which parallels (50a) and is judged perfect in their judgment, is actually somewhat degraded.

(i) Sue's exploration of Easter Island was impressive, then Amy's doing so was a real surprise. 


\section{Conclusion}

I have shown in this paper that the adjective class in Japanese is composed of two subclasses, one of which can be characterized as As of mostly foreign origin, and that this subclass is required to undergo nominalization prior to $\mathrm{PF}$ or at $\mathrm{PF}$ by null nominalizing suffixes. The proposed multi-level nominalization analysis has desirable consequences for ANs, and can be extended to a subclass of Vs in Japanese, which similarly are mostly of foreign origin. Finally, there are desirable consequences for considering VNs to be Vs, which are required to undergo nominalization just like ANs.

However, it remains to be seen what may be the consequences of a finer distinction between lexical and syntactic nominalization for both ANs and VNs. That is, there should be semantic as well as syntactic differences, just as in the case of a result nominal versus an event nominal in English (cf. Grimshaw 1990). ${ }^{19}$ While it is certainly important that this issue be addressed, I will leave it for future research.

\section{References}

Ayano, Seiki-Masaaki Kamiya 2006. Verbal nouns in Japanese are so called for good reasons. Paper presented at the 4th Formal Approaches to Japanese Linguistics Conference, Osaka. (To appear in MIT Working Papers in Linguistics.).

Baker, Mark 2003a. Lexical categories. Verbs, nouns, adjectives. Cambridge University Press, Cambridge.

Baker, Mark 2003b. Verbal adjectives as adjectives without phi-features. In: Yukio Otsu (ed.): Proceedings of the 4th Tokyo Conference on Psycholinguistics, 1-22. Hituzi Syobo, Tokyo.

Bowers, John 1993. The syntax of predication. In: Linguistic Inquiry $24: 591-656$.

Chomsky, Noam 1970. Remarks on nominalization. In: Roderick A. Jacobs- Peter S. Rosenbaum (eds): Readings in English transformational grammar, 184221. Ginn, Waltham.

Chomsky, Noam 1995. The minimalist program. MIT Press, Cambridge MA.

Chomsky, Noam-Morris Halle 1968. The sound pattern of English. Harper \& Row, New York.

Emonds, Joseph 1985. A unified theory of syntactic categories. Foris, Dordrecht.

19 See Miyamoto (1999) and Pak (2001) for their attempts to provide analyses of VNs with respect to the difference between result and event nominals, following Grimshaw (1990).

Acta Linguistica Hungarica 54, 2007 
Emonds, Joseph 1986. Generalized NP-@ inversion: Hallmark of English. In: The syntax of local processes, vol. 1, 165-234. Indiana University Linguistics Club, Bloomington.

Emonds, Joseph 2000. Lexicon and grammar: The English syntacticon. Mouton de Gruyter, Berlin \& New York.

Emonds, Joseph 2005. The computational lexicon. In: English Linguistics $22: 232-66$.

Fu, Jingqi - Thomas Roeper - Hagit Borer 2001. The VP within process nominals: Evidence from adverbs and the VP anaphor do-so. In: Natural Language and Linguistic Theory $19: 549-82$.

Fukui, Naoki 1986. A theory of category projection and its applications. Doctoral dissertation, MIT.

Fukui, Naoki-Hiromu Sakai 2003. The visibility guideline for functional categories: Verb raising in Japanese and related issues. In: Lingua 113:321-75.

Grimshaw, Jane 1990. Argument structure (Linguistic Inquiry Monograph 18). MIT Press, Cambridge MA.

Grimshaw, Jane-Armin Mester 1988. Light verbs and theta-marking. In: Linguistic Inquiry $19: 205-32$.

Harada, Shin-Ichi 1973. Counter equi NP deletion. In: Annual Bulletin (Research Institute of Logopedics and Phoniatrics, University of Tokyo) $7: 113-47$.

Hasegawa, Nobuko 1999. Seesee nihongogaku nyuumon [Introduction to generative grammar]. Taishukan, Tokyo.

Itô, Junko-Armin R. Mester 1995a. The core-periphery structure of the lexicon and constraints on reranking. In: University of Massachusetts Occasional Papers in Linguistics $18: 181-209$.

Itô, Junko - Armin R. Mester 1995b. Japanese phonology. In: John A. Goldsmith (ed.): The handbook of phonological theory, 817-38. Blackwell, Cambridge MA \& Oxford.

Kageyama, Taro 1982. Word formation in Japanese. In: Lingua 57 :215-58.

Kageyama, Taro 1993. Bunpoo to gokeesee [Grammar and word formation]. Hituzi Shoboo, Tokyo.

Kubo, Miori 1992. Syntactic structures and their constructional meanings. Doctoral dissertation, MIT.

Martin, Samuel E. 1975. A reference grammar of Japanese. Yale University Press, New Haven.

Miyagawa, Shigeru 1987. Lexical categories in Japanese. In: Lingua $73: 29-51$.

Miyagawa, Shigeru 1993. Case-checking and minimal link condition. In: MIT Working Papers in Linguistics $19: 213-54$.

Miyamoto, Tadao 1999. The light verb construction in Japanese: The role of the verbal noun. John Benjamins, Amsterdam \& Philadelphia.

Nakamura, Masanori 2005. Case morphology and island repair. Manuscript. Senshu University. (http://people.fas.harvard.edu/ ctjhuang/Course_LSA222/readings /Nakamura200\%3F.pdf)

Narahara, Tomiko 2002. The Japanese copula: Forms and functions. Palgrave Macmillan, Houndmills. 
Nishiyama, Kunio 1999. Adjectives and the copulas in Japanese. In: Journal of East Asian Linguistics $8: 183-222$.

Ochi, Masao 2001. Move F and $g a / n o$ conversion in Japanese. In: Journal of East Asian Linguistics $10: 247-86$.

Pak, Miok 2001. On deriving syntactic properties of verbal nouns in Korean light verb constructions. Doctoral dissertation, Georgetown University.

Riemsdijk, Henk van 1983. The case of German adjectives. In: Frank Henry-Barry Richards (eds): Linguistic categories: Auxiliaries and related puzzles, 223-52. Reidel, Dordrecht.

Saito, Mamoru-Hiroto Hoshi 2000. Japanese light verb constructions and the minimalist program. In: Rogerand Martin-David Michaels - Juan Uriagereka (eds): Step by step. Essays in Honor of Howard Lasnik, 261-95. MIT Press, Cambridge MA.

Shibatani, Masayoshi 1976. The grammar of causative constructions: A conspectus. In: Masayoshi Shibatani (ed.): The grammar of causative constructions (Syntax and semantics, vol. 6), 1-40. John Benjamins, Amsterdam \& Philadelphia.

Shibatani, Masayoshi 1990. The languages of Japan. Cambridge University Press, Cambridge.

Takahashi, Mari 2000. The syntax and morphology of Japanese verbal nouns. Doctoral dissertation, University of Massachusetts, Amherst.

Uehara, Satoshi 1998. Syntactic categories in Japanese: A cognitive and typological introduction. Kurosio, Tokyo.

Urushibara, Saeko 1993. Syntactic categories and extended projections in Japanese. Doctoral dissertation, Brandeis University.

Valois, Daniel 1996. On the structure of the French DP. In: Canadian Journal of Linguistics $41: 349-75$.

Yamakido, Hiroko 2005. The nature of adjectival inflection in Japanese. Doctoral dissertation, Stony Brook University.

Yamakido, Hiroko to appear. The nature of adjectival inflection in Japanese. In: Proceedings of the Workshop in Altaic Formal Linguistics 2. MIT Working Papers in Linguistics .

Yoon, James 1996. A syntactic account of category-changing phrasal morphology: Nominalizations in Korean and English. In: Hee-don Ahn-Myung-Yoon KangYong-Suck Kim - Sookhee Lee (eds): Morphosyntax in generative grammar, 6386. Hankuk, Seoul. 